\title{
Management of post-operative junctional ectopic tachycardia in symptomatic neonates and infants at a tertiary care center in a developing country: Lessons learned!
}

\author{
Mostafa M. Abohelwa MD, Marwan Refaat MD, Amal A. Gharamti MD, Mohamed A Ahmed MD MPH, \\ Amr Elgehiny MD, Issam EI-Rassi MD, Fadi Bitar MD, Mariam Arabi MD
}

\begin{abstract}
Purpose: Junctional ectopic tachycardia (JET) is an uncommon arrhythmia that occurs after surgical correction of congenital heart defects. Data on neonates and infants are limited. This study highlights the epidemiology, incidence, and management of neonates and infants with JET at a tertiary care center in Lebanon.

Methods: We conducted a retrospective chart review on patients hospitalized between January 1, 2013, and December 31, 2017. All patients with documented symptomatic junctional ectopic tachycardia on electrocardiograms who required medical treatment post-surgery were included.

Results: Nine patients were included. The median age was 18 days, and six were males. Six of the nine (66.67\%) were successfully treated with cooling and amiodarone on the initial attempt. The other three cases failed initial treatment with adenosine. However, they were successfully treated with cooling and amiodarone as second-line therapy. All cases of junctional ectopic tachycardia occurred post-surgery at an average of $1.67 \pm 1.11$ days.

Conclusion: Junctional ectopic tachycardia mostly occurs after corrective cardiac surgery and can be successfully treated with cooling and amiodarone. Timely diagnosis significantly affects the outcome.
\end{abstract}

Keywords: Junctional ectopic tachycardia, arrhythmias, neonates, infants.

\section{INTRODUCTION}

Junctional ectopic tachycardia (JET) is a rare type of supraventricular arrhythmia and can be potentially life-threatening. This tachycardia occurs mostly after surgical correction of congenital heart defects. ${ }^{1}$ However, it can present as a primary disorder during infancy, configuring the so-called "congenital JET."2,3 The post-operative form is usually transient and lasts less than one week. The congenital form usually occurs in the first six months of life as a persistent,

Corresponding author: Mariam Arabi Contact Information: Ma81@aub.edu.lb DOI: $10.12746 /$ swrccc.v9i40.881 sustained form. It lasts up to $90 \%$ of the time and is associated with significant morbidity and mortality, with a reported mortality rate of up to $70 \%{ }^{3,4}$ The tachycardia and the loss of synchrony between the atria and ventricles can lead to severe hemodynamic compromise. Treatment usually includes correction of electrolytes, modest hypothermia, avoidance of inotropes, and administration of anti-arrhythmic drugs. ${ }^{1,5}$ Among the latter, amiodarone has been proven to be very effective, with a success rate of up to $70 \%$.,7

Since data related to JET occurring in neonates and infants are scarce from the Middle East, we analyzed all recorded cases of JET in this age category at a tertiary care center in Lebanon hospitalized between January 1, 2013, and December 31, 2017, as a part of a study on arrhythmias in neonates and 
infants done over the same time frame..$^{8,9}$ We aim to highlight the epidemiology, incidence, and management of this rare form of arrhythmia in this age group.

\section{Methods}

\section{HOSPITAL DESCRIPTION AND PATIENT DIAGNOSIS}

The American University of Beirut Medical Center (AUBMC) is a tertiary care center functioning as a referral center at the national and regional levels, located in Beirut, Lebanon, with approximately 200 pediatric heart surgeries per year. A 5-year retrospective chart review was conducted on medical records of patients less than one year old hospitalized between January 1, 2013, and December 31, 2017. Medical records, electrocardiograms (ECGs), laboratory data, and operative reports were reviewed for all cases. All patients with proven symptomatic JET based on ECG findings diagnosed by a pediatric cardiologist who required medical treatment were included.

\section{Classification of CONGENITAL heART DISEASE}

The complexity of congenital heart disease was divided into three categories using the American College of Cardiology Task Force 1 of the $32^{\text {nd }}$ Bethesda Conference. This classification divided congenital heart lesions into three categories: simple lesions, moderate lesions, and complex lesions. ${ }^{10} \mathrm{We}$ used the same scheme to categorize our patients.

\section{TREATMENT SUCCESS}

Treatment success was defined as the return of normal sinus rhythm on an ECG.

\section{Statistical Analysis}

Descriptive statistical analysis was applied to the nine cases. Maximum, minimum, mean, median, upper, and lower quartiles were reported for age and time post-surgery.

\section{EthicAL CONSIDERATIONS}

The Institutional Review Board (IRB) at AUBMC reviewed and approved the conduct of this study under a waiver of informed consent.

\section{RESULTS}

\section{Baseline Characteristics}

Over the five-year period, nine cases of JET were identified (Table 1). The median age was 18 days, and six were males. The total number of cardiac surgeries done on neonates and infants during this period was 190 , and the incidence of JET who required amiodarone treatment among hospital admissions in this age category is $47 / 1000$. All cases of JET occurred post-surgery at an average of $1.67 \pm 1.11$ days (Table 2). All subjects were born maturely; eight out of nine had normal birth weights. No cases of congenital JET were identified. Consanguinity was reported in two cases.

\section{TREATMENT AND OUTCOME}

Six patients out of nine $(66.67 \%)$ were successfully treated with cooling and amiodarone on the initial treatment. The other three cases failed the initial treatment with adenosine. This helped the medical team confirm the diagnosis of JET, and these patients were then successfully treated with cooling and amiodarone.

\section{Complexity of CONGENITAL heART DiseAse}

Five of our nine patients had complex heart lesions, four had moderate heart lesions, and no cases had simple heart lesions.

\section{RELATIONSHIP WITH ELECTROLYTES}

Five patients had hypokalemia $\left(\mathrm{K}^{+}<3.5 \mathrm{meq} / \mathrm{L}\right)$ before the time of arrhythmia. Three subjects had mild acidosis, with a pH between 7.25 and 7.35 before the time of arrhythmia. All subjects had normal magnesium levels before the time of arrhythmia (2.5-4 meq/l). 
Table 1. Patients Characteristics

\begin{tabular}{|c|c|c|c|c|c|c|c|c|c|c|c|}
\hline Subject & $\begin{array}{l}\text { Age/ } \\
\text { Sex }\end{array}$ & CHD & $\begin{array}{l}\text { 1st line of } \\
\text { Treatment }\end{array}$ & $\begin{array}{l}\text { Persistence } \\
\text { of } \\
\text { Arrhythmia }\end{array}$ & $\begin{array}{l}\text { 2nd line of } \\
\text { Treatment }\end{array}$ & $\begin{array}{c}\text { Time } \\
\text { Post- } \\
\text { Surgery } \\
\end{array}$ & Potassium & PH & $\begin{array}{l}\text { Weight } \\
\text { At } \\
\text { Surgery }\end{array}$ & $\begin{array}{c}\text { Complexity } \\
\text { of Heart } \\
\text { Lesion } \\
\end{array}$ & Consanguinity \\
\hline 1 & $0.6 / \mathrm{M}$ & \begin{tabular}{|l|} 
TGA/ \\
VSD/PDA
\end{tabular} & Amiodarone & No & No & 2 & Normal & $\mathrm{N} / \mathrm{A}$ & $\begin{array}{l}2.6 \\
\text { Low }\end{array}$ & 3 & No \\
\hline 2 & $10 / \mathrm{M}$ & $\begin{array}{l}\text { Complete } \\
\text { AV canal }\end{array}$ & Amiodarone & No & No & 0 & Low (3) & $\begin{array}{l}\text { Mild } \\
\text { acidosis }\end{array}$ & Normal & 2 & Yes \\
\hline 4 & $0.5 / \mathrm{M}$ & $\begin{array}{l}\text { TGA/ } \\
\text { VSD/PDA }\end{array}$ & Amiodarone & No & No & 4 & Low (2.9) & Normal & Normal & 3 & No \\
\hline 5 & $0.3 / \mathrm{F}$ & TGA & Amiodarone & No & No & 2 & Normal & Normal & Normal & 3 & No \\
\hline 6 & $4 / F$ & TAPVR & Adenosine & Yes & Amiodarone & 1 & Low (3.1) & Normal & Normal & 3 & No \\
\hline 7 & $0.4 / \mathrm{M}$ & TOF & Amiodarone & No & No & 2 & Low (3.2) & Normal & Normal & 2 & No \\
\hline
\end{tabular}

M-male; F-female; TGA-transposition of great arteries; VSD-ventricular septal defect; PDA-patent ductus arteriosus; TAPVR-total anomalous pulmonary venous return; TOF-Tetralogy of Fallot; TA-tricuspid atresia; Mild acidosis defined as PH between (7.35-7.25); normal potassium between 3.5 and 5, N/A Not Available.

\section{Discussion}

\section{Pathophysiology}

Junctional ectopic tachycardia is a supraventricular arrhythmia that originates in the atrioventricular AV node and AV junction. Its incidence is rare, and it doesn't involve a re-entry circuit. Therefore, atrioventricular reciprocating tachycardia (AVRT) and atrioventricular nodal re-entry tachycardia (AVNRT) are not considered JET (Figure 1).

Table 2. Cohort Age and Interval Between Surgery and Arrhythmia

\begin{tabular}{|l|c|c|}
\hline & $\begin{array}{c}\text { Age } \\
\text { (Months) }\end{array}$ & $\begin{array}{c}\text { Time Post-Surgery } \\
\text { (Days) }\end{array}$ \\
\hline Maximum & 10 & 4 \\
\hline Upper quartile & 6 & 2 \\
\hline Median & 0.6 & 2 \\
\hline Mean & 3.24 & 1.67 \\
\hline Lower quartile & 0.4 & 1 \\
\hline Minimum & 0.3 & 0 \\
\hline
\end{tabular}

\section{Diagnosis}

The diagnosis of JET is made by the typical appearance on a 12-lead ECG. A narrow QRS configuration at a rate of 170 to 260 with $\mathrm{AV}$-dissociation is characteristic (Figure 2). ${ }^{11,12}$ Adenosine administration can help confirm the diagnosis, and it was used to confirm the diagnosis in three of our patients.

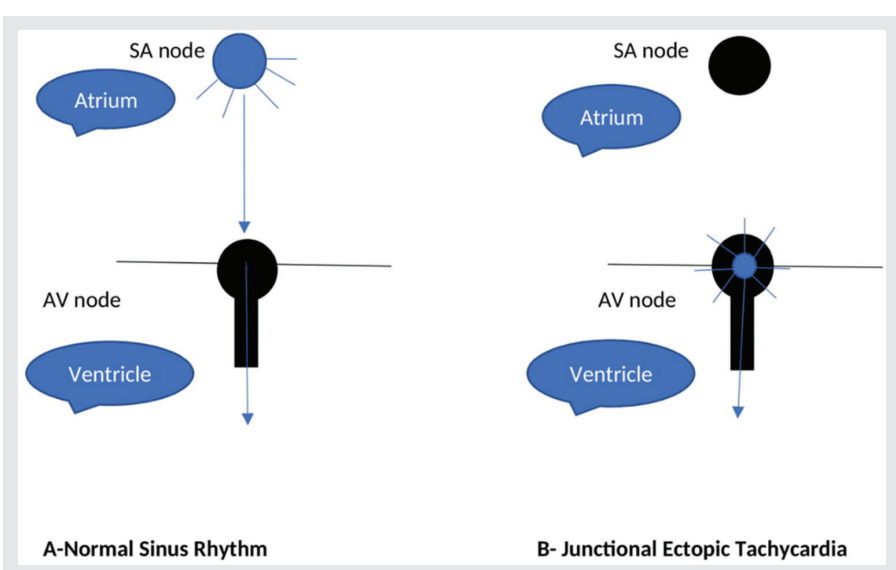

Figure 1. A schematic representation of a normal sinus rhythm (A) and junctional ectopic tachycardia (B). 


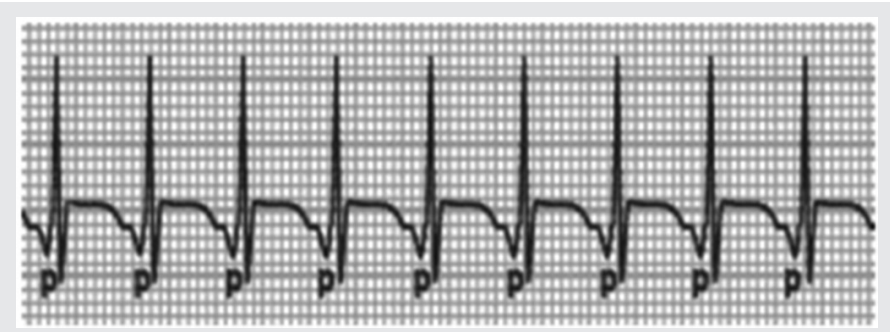

Figure 2. Characteristic appearance of JET on an ECG.

Adenosine will block the retrograde AV-conduction but will not reduce the ventricular rate. Therefore, the response to adenosine is the persistence of tachycardia. This is in contrast to AVNRT in which the arrhythmia will be terminated. ${ }^{13}$

\section{TREATMENT}

Treatment is indicated in all symptomatic patients. However, treating asymptomatic patients with heart rates less than 150 beats per minute (BPM) is debatable. $^{7}$ Nonetheless, monitoring asymptomatic patients is crucial, since JET can lead to hemodynamic compromise, which can be potentially life-threatening. Therefore, our approach was directed towards the treatment of all cases, regardless of symptomatology. In our institution, some patients were treated with cooling only; others required amiodarone, and those were the ones who were included in this paper. The treatment goal aimed to reduce the heart rate through correcting electrolytes (magnesium and potassium), acidosis (taking ABGs at the time of arrhythmia by the medical team occurred in eight out of the nine cases), cooling the patient, and then administering the antiarrhythmic medication. ${ }^{14}$ It has been previously shown that cooling the patient to a moderate core temperature of $35^{\circ} \mathrm{C}$ usually decreases the heart rate but without restoring normal rhythm. ${ }^{1,5,15}$ As previously stated, treatment success was defined as the return of normal sinus rhythm on ECG. This was based on the fact that the baseline heart in neonates is around 150 beats per minute (BPM). Therefore, our team used a normal sinus ECG as the standard of treatment success in contrast to the published data that define treatment success as the return of heart rate to less than 150 BPM. Moreover, this standard heart rate cannot be used in neonates. ${ }^{6}$ In other cases, when the heart rate was acceptable for the patient, no medical therapy was applied, with only observation applied to patients with a heart rate of less than 150 BPM. This paper focuses only on those who received medical treatment.

Amiodarone was the drug of choice by our cardiologists since it is the safest drug for use in the post-operative settings. It was initially used in six out of nine cases, with a success rate in terminating the JET, reaching $66.67 \%$. However, adenosine was initially used in three cases and failed to terminate the arrhythmia that was initially interpreted as AVNRT. Although adenosine is not the drug of choice therapeutically, it helps confirm the diagnosis of JET. Following failed attempts with adenosine, amiodarone was used, and it terminated the arrhythmia successfully. The amiodarone loading dose was $5 \mathrm{mg} / \mathrm{kg}$ intravenous drip over 30 minutes followed by a continuous infusion of $5-15 \mathrm{mcg} / \mathrm{kg} / \mathrm{minute}$ similar to what is being used and reported previously. $3,13,16$

The success rate was $66.67 \%$ with amiodarone on the first attempt and $100 \%$ after the second attempt. This is consistent with most of the published data on amiodarone. Data coming from the Middle East are scarce. In addition, published data about JET incidence in infants and its management are limited. To our knowledge, this is the first study from the Middle East on JET in this age group. Abdelaziz et al. from Egypt reported a higher JET incidence, reaching 27 percent. ${ }^{17}$ However, it included a large cohort of patients of different age groups, whereas this study included only infants. Another study done by Ismail et al. from Saudi Arabia included children less than two years and showed a higher JET incidence. ${ }^{18}$ However, amiodarone was used in only 29 percent of patients, and it was associated with prolonged ICU stays. The reason for prolonged ICU stay was not clear as the study was limited regarding the collected variables, and most of those patients required mechanical ventilation.

Some reports have described the use of procainamide in $\mathrm{JET},{ }^{19}$ but this is not available in our institution. In addition, beta-blockers are usually avoided in the immediate post-operative setting due to the negative chronotropic effect of these medications because these patients have a predisposition to complete heart block. ${ }^{19}$ Data regarding the use of digoxin are not promising for JET. 


\section{LIMITATIONS}

The study was limited by a small number of infants who had cardiac surgery. These infants were likely monitored more closely than other infants, and any arrhythmias were picked up early during their postoperative care. In addition, the study did not include any infants or neonates that who did not have cardiac surgery. The study took place in a single center, and this may limit its generalization to other centers. These results may stimulate other centers to review the results and potentially create a large multicenter databases.

\section{Conclusion}

In conclusion, there are various medical treatment approaches for JET in neonates and infants. However, highly successful treatment can be established by correcting the electrolytes and acidosis, cooling the infant, and starting amiodarone. Adenosine does not terminate the arrhythmia but helps confirm the diagnosis.

Article citation: Abohelwa MM, Refaat M, Gharamti AA, Ahmed MA, Elgehiny A, El-Rassi I, Bitar F, Arabi $M$. Management of post-operative junctional ectopic tachycardia in symptomatic neonates and infants at a tertiary care center in a developing country: Lessons learned! The Southwest Respiratory and Critical Care Chronicles 2021;9(40):14-19

From: Department of Internal Medicine (MMA), Texas Tech University Health Sciences Center, Lubbock, Texas; Department of Internal Medicine (MR), Cardiology Division, American University of Beirut Medical Center, BeirutLebanon; Department of Internal Medicine, Yale School of Medicine, Waterbury Hospital, Connecticut, USA. Department of Family Medicine (MAA), American University of Beirut Medical Center, Beirut-Lebanon; Department of Pediatrics (AE), University of Texas at Houston, Texas, USA; Department of Surgery (IER), American University of Beirut Medical Center, Beirut-Lebanon; Department of Paediatrics (FB, MA), Cardiology Division, American University of Beirut Medical Center, Beirut-Lebanon

Submitted: 6/23/2021

Accepted: 7/6/2021

Reviewer: Scott Shurmur MD

Conflicts of interest: none

This work is licensed under a Creative Commons Attribution-ShareAlike 4.0 International License.

\section{REFERENCES}

1. Cabrera AD, Rodrigo DC, Galdeano JM, et al. The treatment of postoperative junctional ectopic tachycardia. Anales Espanoles de Pediatria 2002;56(6):505-509.

2. Coumel P, Fidelle J, Attuel P, et al. Congenital bundle-of-his focal tachycardias. Cooperative study of 7 cases. Archives des Maladies du Coeur et des Vaisseaux 1976;69(9):899-909.

3. Sarubbi B, Vergara P, D'Alto M, et al. Congenital junctional ectopic tachycardia: presentation and outcome. Indian Pacing Electrophysiology J 2003;3(3):143.

4. Dodge-Khatami A, Miller O, Anderson R, et al. Impact of junctional ectopic tachycardia on postoperative morbidity following repair of congenital heart defects. European J CardioThoracic Surgery 2002;21(2):255-259.

5. Pfammatter J-P, Paul T, Ziemer G, et al. Successful management of junctional tachycardia by hypothermia after cardiac operations in infants. The Annals Thoracic Surgery 1995;60(3):556-560.

6. Villain E, Vetter V, García JM, et al. Evolving concepts in the management of congenital junctional ectopic tachycardia. A multicenter study. Circulation 1990;81(5):1544-1549.

7. Sarubbi B, Musto B, Ducceschi V, et al. Congenital junctional ectopic tachycardia in children and adolescents: a 20 year experience based study. Heart 2002;88(2):188-190.

8. Abohelwa M, Refaat M, Ahmed MA, et al. Arrhythmia in neonates and infants at a tertiary care center. J American College Cardiology 2021;77(18_Supplement_1):397-397.

9. Refaat M, Abohelwa MM, Ahmed M, et al. Arrhythmias in neonates and infants at a tertiary care center. Cureus 2021; $13(1)$.

10. Overview of Adult Congenital Heart Disease / Congenital Heart Disease-Cove Point Foundation (http://www.pted. org/?id=overview1).

11. Parra DA, Totapally BR, Zahn E, et al. Outcome of cardiopulmonary resuscitation in a pediatric cardiac intensive care unit. Critical Care Medicine 2000;28(9):3296-3300.

12. Tharakan JA, Sukulal K. Post cardiac surgery junctional ectopic tachycardia: a 'Hit and Run'tachyarrhythmia as yet unchecked. Annals of Pediatric Cardiology 2014;7(1): 25.

13. Haas N, Plumpton K, Justo R, et al. Postoperative junctional ectopic tachycardia (JET). Zeitschrift für Kardiologie 2004;93(5):371-380.

14. Dorman BH, Sade RM, Burnette JS, et al. Magnesium supplementation in the prevention of arrhythmias in pediatric patients undergoing surgery for congenital heart defects. American Heart J 2000;139(3):522-528.

15. Guccione P, Di DC, Papa M, et al. Hypothermia treatment of junctional ectopic tachycardia after surgical repair of congenital heart defects. Giornale Italiano di Cardiologia 1990;20(5):415-418. 
16. Junctional ectopic tachycardia medication: antiarrhythmic agents (https://emedicine.medscape.com/article/898989medication).

17. Abdelaziz O, Deraz S. Anticipation and management of junctional ectopic tachycardia in postoperative cardiac surgery: Single center experience with high incidence. Annals of Pediatric Cardiology 2014;7(1):19.
18. Ismail MF, Arafat AA, Hamouda TE, et al. Junctional ectopic tachycardia following Tetralogy of Fallot repair in children under 2 years. J Cardiothoracic Surgery 2018;13(1):60.

19. Walsh EP, Saul JP, Sholler GF, et al. Evaluation of a staged treatment protocol for rapid automatic junctional tachycardia after operation for congenital heart disease. J American College Cardiology 1997;29(5):1046-1053. 